\title{
Large congenital melanocytic nevus
}

INSERM

\section{Source}

INSERM. (1999). Orphanet: an online rare disease and orphan drug data base. Large congenital melanocytic nevus. ORPHA:626

A large, or giant, congenital melanocytic nevus (LCMN or GCMN) is a pigmented skin lesion of more than $20 \mathrm{~cm}$ - or $40 \mathrm{~cm}$ - respectively, projected adult diameter, composed of melanocytes, and presenting with an elevated risk of malignant transformation. 